\title{
APARATO CONCEITUAL SOBRE ÁREAS ÚMIDAS (WETLANDS) NO BRASIL: DESAFIOS E OPINIÕES DE ESPECIALISTAS
}

\author{
CONCEPTUAL FRAMEWORK ON WETLANDS IN BRAZIL: \\ CHALLENGES AND EXPERT OPINIONS
}

\author{
APARATO CONCEPTUAL SOBRE ÁREAS HÚMEDAS (WETLANDS) \\ EN BRASIL: DESAFÍOS Y OPINIONES DE ESPECIALISTAS \\ Cecília Siman Gomes - Universidade Federal de Minas Gerais - Minas Gerais - Belo Horizonte - Brasil \\ ceciliasiman@gmail.com
}

\author{
Antônio Pereira Magalhães Junior - Universidade Federal de Minas Gerais - \\ Minas Gerais - Belo Horizonte - Brasil \\ magalhaesufmg@yahoo.com.br
}

\section{Resumo}

As Áreas úmidas (AUs) são ecossistemas complexos, integradas por variáveis hidrológicas, climáticas, geomorfológicas, pedológicas e bioquímicas, que desempenham funções ambientais relevantes. A complexidade encontrada nos estudos das AUs explica a dificuldade de estabelecer consensos na sua definição, tanto no meio científico quanto jurídico. No Brasil, ainda são poucos os estudos que buscam investigar as AUs sob o ponto de vista conceitual, o que causa problemas na concepção e aplicação da legislação referente à sua proteção. A visão do geógrafo, horizontalizada e multidisciplinar, é potencialmente útil para as pesquisas sobre AUs. Neste contexto, esta pesquisa teve por objetivo desenvolver uma proposta conceitual de referência, visando melhorar a compreensão do conceito e facilitar a sua aplicação. No desenvolvimento dessa proposta, foi realizada uma investigação e análise teórico-reflexiva das definições presentes na literatura científica e nos dispositivos legais, nacionais e internacionais, complementada e articulada com opiniões imprescindíveis de especialistas em AUs. A proposta resultou em uma síntese conceitual que inclui características relativas à formação, identificação e delimitação das AUs, para visar a maiores concordâncias por pesquisadores, analistas, técnicos e gestores de diferentes áreas do conhecimento e sua aplicação na área ambiental.

Palavras-chave: Áreas úmidas, ecossistemas, hidrogeomorfologia.

\begin{abstract}
Wetlands are complex ecosystems integrated by hydrological, climatic, geomorphological, pedological, and biochemical variables that play relevant environmental functions. The complexity found in wetland studies explains the difficulty of establishing consensus in its definition, both in scientific and legal terms. Research related to the conceptual basis is necessary to resolve problems in the definition and application of legislation regarding their protection. The geographer's vision, horizontal and multidisciplinary, is potentially useful for wetland research. In this context, this research aimed to develop a conceptual reference proposal, seeking to facilitate its application. Theoretical-reflective research was carried out on the definitions present in the scientific and legal literature, national and international, complemented and articulated with essential opinions of specialists. The proposal resulted in a conceptual synthesis that includes characteristics related to the formation, identification, and delimitation of wetlands, seeking greater agreement by various professionals and their application in the field.
\end{abstract}

Keywords: Wetlands, ecosystems, hydrogeomorphology. 
Resumen

Los humedales son ecosistemas complejos, integrados por variables hidrológicas, climáticas, geomorfológicas, pedológicas y bioquímicas, que desempeñan funciones ambientales relevantes. La complejidad encontrada en los estudios de los humedales explica la dificultad de establecer consensos en su definición, tanto en el medio científico cuanto jurídico. En Brasil, todavía son pocos los estudios que buscan investigar los humedales desde el punto de vista conceptual, lo que causa problemas en la concepción y aplicación de la legislación para su protección. La visión del geógrafo, horizontalizada y multidisciplinar, es potencialmente útil para las investigaciones sobre los humedales. Dentro de ese contexto, esta investigación tuvo por objetivo desarrollar una propuesta conceptual de referencia, buscando mejorar la comprensión del concepto y facilitar su aplicación. Para desarrollar esta propuesta, se desenvolvió una investigación y análisis teórico-reflexivo de las definiciones presentes en la literatura científica y de los dispositivos legales, nacionales e internacionales, complementada y articulada con opiniones imprescindibles de especialistas. La propuesta tuvo como resultado una síntesis conceptual que incluye características relativas a la formación, identificación y delimitación de los humedales, visando mayores concordancias de investigadores, analistas, técnicos y gestores de las diferentes áreas de conocimiento y su aplicación en el área ambiental.

Palabras clave: Humedales, ecosistemas, hidrogeomorfología.

Introdução

As Áreas úmidas (AUs), internacionalmente conhecidas pelo termo wetlands, cobrem aproximadamente $11 \%$ das superfícies tropicais (Mitsch; Gosselink, 2007) e cerca de 20\% do território brasileiro (Junk et al., 2014; Cunha; Piedade; Junk, 2015). São considerados um dos ecossistemas mais relevantes do mundo em termos ambientais, pois além de apresentarem uma diversidade específica de fauna e flora, atuam na recarga de aquíferos, na melhoria da qualidade da água, na retenção de carbono orgânico, na regulação de ciclos biogeoquímicos, no controle de inundações, na regulação de variáveis climáticas, bem como no fornecimento de combustíveis fósseis, água e alimentos (Barbier; Acreman; Knowler, 1997; Mitsch; Gosselink, 2007; Reddy; Delaune, 2008; Junk et al., 2014).

Até a metade do século XX ainda não havia uma preocupação mundial em se definir o conceito de AUs. As políticas nacionais incentivavam a ocupação e a drenagem dessas áreas, vistas como terrenos brejosos sem utilidade e/ou insalubres. Estima-se que já houve uma perda de aproximadamente $50 \%$ das AUs no mundo devido aos processos de drenagem artificial para a agropecuária e a ocupação urbana (Mitsch; Gosselink, 2007). A degradação dessas áreas resultou em inúmeros impactos ambientais, como a perda da biodiversidade de espécies aquáticas, a redução da disponibilidade hídrica e a contaminação das águas subterrâneas, culminando na necessidade de se definir e investigar a importância das AUs e de se estabelecer políticas para gestão e conservação das áreas remanescentes. 
O primeiro encontro internacional que marcou a valorização e a discussão sobre as AUs ocorreu em 1971, na Convenção sobre Zonas Úmidas de Importância Internacional, na cidade de Ramsar, no Irã, atualmente mais conhecida como a Convenção de Ramsar. A sua pauta inicial era a proteção de aves aquáticas, mas nas últimas décadas foi ampliada para a manutenção de outras espécies e a sua relevância ambiental. O Brasil tornou-se membro da Convenção em 1993, ratificando-a três anos depois por meio do Decreto $\mathrm{n}^{\circ} 1.905$ (Brasil, 1996), mas pouco avançou na concepção e aplicação de critérios sobre as AUs, o que gerou a sua marginalização no âmbito conceitual e legal para fins de gestão e proteção. O conceito apresentado pelo Código Florestal por meio da Lei $\mathrm{n}^{\mathrm{o}} 12.651$ (Brasil, 2012), além de ser dissonante daqueles que se tem produzido cientificamente e legalmente na literatura nacional e internacional, não apresenta critérios de proteção. Pelo contrário, o Código Florestal fragilizou a proteção das AUs brasileiras, sinalizando a demanda urgente de propostas de definição e classificação cientificamente embasadas para apoiar o seu reconhecimento legal e social (Junk et al., 2014; Cunha; Piedade; Junk, 2015).

Especialmente para efeitos legais, as AUs não são facilmente definidas, pois apresentam condições físicas e biológicas diversas, dimensões variadas e ainda podem ter gênese associada a influências antrópicas (Mitsch; Gosselink, 2007). A complexidade na definição conceitual resulta, muitas vezes, em definições pouco claras, por vezes restritas ou genéricas, e/ou mesmo contraditórias. Termos adotados como pântano, charco, brejo, manguezal, turfeira, dentre outros, ilustram os desafios para uma maior precisão na concepção das AUs (Cowardin et al., 1979) e a necessidade das próprias definições virem acompanhadas, muitas vezes, de exemplos de tipos de AUs.

Para a compreensão e definição das AUs, diferentes áreas do conhecimento devem ser contempladas, pois suas funções são regidas por variáveis hidrológicas, hidrogeológicas, climáticas, geomorfológicas, pedológicas, químicas e biológicas, bem como por suas diferentes formas de interação (Lefor; Kennard, 1977; Tiner, 1999; Reddy; Delaune, 2008). Dependendo da formação e do campo de atuação de cada pesquisador, há diferentes definições de AUs. Por exemplo, a concepção dos hidrólogos tende a enfocar o regime das águas e sua relação com a topografia, enquanto a dos pedólogos tende a centrar-se no estudo da presença de 
solos hidromórficos. Já a dos botânicos tende a focar na ocorrência de determinadas espécies ou comunidades. Nesse sentido, para avançar na proteção das AUs, é imprescindível que se tenha uma definição que abarque seus diversos tipos, dialogue com diferentes campos de pesquisa e seja suficientemente precisa e aplicável.

A Geografia pouco tem se dedicado a pesquisas sobre as AUs no Brasil e no mundo. Quando realizadas, geralmente se limitam a um estudo de caso específico em termos de gênese e caracterização. Entretanto, a visão multidisciplinar do geógrafo, integradora de variáveis ambientais, tem potencial de contribuir para os estudos das AUs, considerando-as objetos de investigação de suas diversas disciplinas como unidades funcionais e/ou da paisagem nos quais os aspectos físicos e humanos, interagem no tempo e no espaço. Assim, a Geografia pode contribuir para os avanços na definição das AUs e para a compreensão dos processos envolvidos na sua espacialização, configuração e funcionamento.

Nesse sentido, diante da necessidade de refinar a base teórica e analítica, bem como de aprimorar e expandir a base de proteção legal das AUs no Brasil, o principal objetivo da pesquisa foi desenvolver uma proposta conceitual de referência de AUs, visando melhorar a compreensão e facilitar a sua aplicação, bem como contribuir para a proteção, gestão e futuras pesquisas científicas das AUs.

\section{Procedimentos Metodológicos}

Inicialmente, foi realizado amplo levantamento teórico-reflexivo das principais definições advindas da literatura científica e legal relativo às AUs, no âmbito nacional e internacional, e foram selecionadas, ao todo, 30 definições, apresentadas em um quadro síntese ao final do item "Bases teórico-conceituais e abordagens legais das AUs". Ressalta-se que a maior parte das definições provém da língua inglesa e que a tradução literal foi feita visando manter-se o mais fiel possível à fonte. Com base na pesquisa, foram elaborados os seguintes questionamentos sobre as AUs: O que define uma AU? As AUs são sempre ambientes de interface entre sistemas aquáticos e terrestres? Um corpo d'água é uma AU ou pode incluir uma AU? Como se forma uma AU e como ela se mantém ativa? Quais são as características das AUs? Essas características estarão sempre presentes? O que é relevante identificar e caracterizar para fins de proteção e gestão? 
Tais questões, juntamente com a seleção de ilustrações potenciais de AUs, apresentadas ao longo do item "Considerações sobre as AUs sob a ótica dos entrevistados", serviram como base para a elaboração do roteiro e da condução das entrevistas.

Os entrevistados foram selecionados na Plataforma Lattes do CNPq, com base na busca de palavras chaves como wetlands, áreas úmidas, áreas inundáveis e alagadas e na formação acadêmica (principalmente em ciências biológicas, ecologia, agronomia, engenharia florestal, geografia e geologia), atuação profissional (especialmente aqueles associados a instituições de pesquisa) e produção científica, sendo priorizados aqueles com produção bibliográfica diretamente associada às AUs. De uma consulta de mais de 700 currículos, foram selecionados 34 especialistas, dos quais 29 estavam com endereço de e-mail disponível para fazer o convite para participar da pesquisa, sob anonimato. Do total, 9 aceitaram a participação e 5 prosseguiram com o agendamento, sendo 4 biólogos e 1 geólogo, constando pesquisadores do Instituto Nacional de Áreas Úmidas, no Mato Grosso, e de universidades/institutos de pesquisa, situados no Rio Grande do Sul e em Minas Gerais. Seguindo estes procedimentos metodológicos, nenhum geógrafo foi selecionado para participar da pesquisa, refletindo a pouca inserção da geografia nos estudos sobre AUs no país. As entrevistas, realizadas entre novembro de 2015 e janeiro de 2016, foram do tipo semiestruturadas ${ }^{1}$ e analisadas pelo método de análise de conteúdo ${ }^{2}$ em categorias. Mais informações e detalhes podem ser acessados em Gomes (2017).

A proposta conceitual foi elaborada a partir da articulação e análise do referencial teórico estudado e as percepções dos entrevistados, envolvendo principalmente as características que assumem papel central na definição, formação, identificação, delimitação e classificação das AUs para permitir um maior entendimento e aplicação do conceito.

\section{Bases teórico-conceituais e abordagens legais das AUs}

Uma das primeiras definições de AUs foi apresentada em 1956 pelo USFWS $^{3}$, através da publicação comum ente referida como Circular 39 (Shaw; Fredine, 1956). A definição ( $\mathrm{n}^{\circ}$ 1, Quadro 1) teve como objetivo delimitar as áreas que atuam como importantes habitats de aves aquáticas e incluiu 20 tipos de AUs, servindo tanto para atender cientistas e gestores 
públicos, quanto para embasar o primeiro sistema de classificação americano de AUs (NRC,1995; Mitsch; Gosselink, 2007). Nota-se que a definição distinguiu AUs de córregos perenes, reservatórios e lagos profundos, mas sem estabelecer um limite de profundidade entre as AUs e os ecossistemas aquáticos. A presença de uma vegetação emergente na definição, apesar de não obrigatória, auxilia na distinção das AUs, pois geralmente é típica de corpos d'água rasos e está associada aos habitats de aves aquáticas. A definição também distingue as AUs de superfícies com águas temporárias que pouco influenciam no desenvolvimento de uma vegetação adaptada aos solos úmidos.

Com a crescente preocupação com a conservação dos principais habitats das aves aquáticas, a Convenção de Ramsar utilizou como limite de definição das zonas úmidas (n 2, Quadro 1) os seis metros na maré baixa para áreas costeiras, para proteger as áreas de pastejo de aves aquáticas (Junk et al., 2014). Conforme Scott e Jones (1995), os países que aderiram à Convenção de Ramsar apresentam dificuldades em adotar o conceito, pois além de muito amplo, provoca dificuldades de delimitação, especialmente para os recifes de coral, que muitas vezes se estendem além dos seis metros.

Nos Estados Unidos, a formulação de leis e regulamentos relativos à preservação das AUs demandou definições e inventários mais precisos para identificação das AUs prioritárias à conservação (Scott; Jones, 1995; Finlayson; Davidson, 1999). A proposta de Cowardin et al. (1979) (n ${ }^{\circ} 6$, Quadro 1), elaborada pelo USFWS em parceria com o NRC ${ }^{4}$, substituiu a definição de 1956 e introduziu os parâmetros plantas hidrófitas ${ }^{5}$ e solos hídricos ${ }^{6}$ no conceito para, principalmente, estimular o desenvolvimento de listas e inventários regionais para manejo e proteção de AUs (NRC, 1995; Mitsch; Gosselink, 2007). Contudo, tal definição pode excluir alguns tipos de AUs, em função da existência de AUs que apresentam substratos rochosos sem a presença de hidrófitas, do problema da definição precisa do período vegetativo das espécies e do fato das AUs não cessarem diversas funções ecológicas fora deste período (NRC, 1995; Tiner, 1999). Além disso, definir como obrigatória a presença de vegetação pode estimular a sua supressão por proprietários de terra, como foi verificado nos EUA (Mitsch; Gosselink, 2007).

A definição de Cowardin et al. (1979) também considera as AUs como áreas de transição entre sistemas terrestres e aquáticos, o que leva 
a entender, a princípio, que uma AU se situa entre um ambiente seco e outro aquático. Até o final do século XX, as AUs foram consideradas diversas vezes como ecótonos ${ }^{7}$ (Neiff, 2003), provavelmente porque muitas AUs são planícies de inundação e apresentam uma composição específica de sistemas de transição entre terra e água, contendo espécies de ambos os sistemas (Tiner, 1999). Contudo, Neiff; Iriondo; Carignan (1994) e Neiff (2003) argumentam que, dependendo do contexto físico, extensão e complexidade ecológica, as planícies de inundação formam um sistema único, pois suas características estruturais e funcionais são próprias e relativamente estáveis ao longo do tempo e no espaço, como pode ser entendido na sua definição (n 14, Quadro 1). Lyon e Lyon (2011) ( $\mathrm{n}^{\circ} 21$, Quadro 1) considera a AU como uma mistura de características de ambientes terrestres ou aquáticos, que cria um habitat único para a vida e seus processos.

Em 1995, o NRC revisou as bases científicas para identificação e delimitação das AUs e formulou um conceito de referência $\left(n^{\circ} 15\right.$, Quadro 1). Apesar de pouco usual, ainda é considerada a definição científica mais abrangente já desenvolvida, pois reúne os processos básicos que caracterizam as AUs e utilizam solos hídricos e/ou vegetação hidrófita como características comuns de diagnóstico e não como necessidades absolutas. Além disso, o NRC não define as AUs como áreas de transição entre sistemas terrestres e aquáticos por considerar a expressão controversa (Mitsch; Gosselink, 2007).

Na Europa, destacam-se definições concebidas na França e na Espanha. O Museu Nacional de História Natural francês apresentou duas definições, a primeira incorporada na sua Lei da Água ( $n^{\circ} 12$, Quadro 1) e a segunda $\left(\mathrm{n}^{\circ} 13\right.$, Quadro 1), mais citada no meio científico, facilita a interpretação ao incluir a localização espacial (O. Cizel, 2010).

Na Espanha, a Agência de Água da Catalunha elaborou uma definição $\left(\mathrm{n}^{\circ} 8\right.$, Quadro 1) que permite a inclusão de massas d'água profundas. Na Andaluzia, o Plano governamental de AUs, elaborado por pesquisadores de diversas áreas, apresentou uma proposta de definição de referência ( $\mathrm{n}^{\circ}$ 19, Quadro 1). O Plano reconhece que é um grande desafio definir e delimitar as AUs quando são sistemas de transição entre ambientes aquáticos e terrestres, pois são heterogêneas e muito dinâmicas em termos espaço-temporais. Dessa forma, para se chegar a um conceito de AUs é necessário primeiro partir do que deve ou não 
ser considerado em sua definição, para depois assumi-lo. Escolhendo o gradiente de profundidade como a variável importante no funcionamento dos ecossistemas aquáticos, devido a ação da gravidade e ao alcance da luz para os efeitos da fotossíntese, o Plano distingue as características ecológicas de lagos, lagoas e AUs através de um modelo hipotético de um ecossistema úmido em torno de um lago profundo, que começa a partir do nível mínimo de inundação do lago até o contato com o terreno permanentemente não saturado, da seguinte forma: lagos com profundidade maior que 8 metros; lagoas com profundidade entre 2 e 8 metros; e AUs com profundidade até 2 metros abaixo do nível máximo de inundação. Contudo, o Plano ressalta que, dependendo das variações climáticas de uma região, uma mesma AU poderá apresentar, ao longo do tempo, características de solos úmidos, de ecossistemas aquáticos e áreas terrestres (Gil, 2002).

O Plano de Andaluzia demonstra que a água, o relevo deprimido e seus materiais e a biota explicam as diferenças entre AUs e outros ecossistemas aquáticos ou terrestres. Estes fatores, mais do que uma soma no espaço e no tempo, geram um sistema complexo de interações geofísicas e bioquímicas, onde os componentes abióticos superiores influenciam os componentes bióticos inferiores, os quais, em menor escala, também influenciam os superiores. Dessa forma, a definição de AUs deve considerar seus componentes hidrológicos, geomorfológicos, pedológicos e bióticos, fornecer indicadores para identificar e delimitar AUs em campo e ser operacional de modo a facilitar o estabelecimento de ações integradas de gestão e conservação (Gil, 2002).

No hemisfério sul, o Departamento de Meio Ambiente australiano adotou uma definição ( $\mathrm{n}^{\circ}$ 17, Quadro 1) que inclui AUs subterrâneas, o que não está explícito nas outras definições. No seu relatório de manejo de AUs urbanas, um item comum na definição ( $n^{\circ} 23$, Quadro 1) é a presença de águas estagnadas ou com dinâmica lenta, mas nem todos os conceitos na literatura convergem para essa característica. Na legislação brasileira, a definição do Código Florestal ( $n^{\circ}$ 27, Quadro 1) exclui as AUs permanentes e não esclarece se AUs são somente aquelas inundadas por cursos d'água. O INAU ${ }^{8}$ amplia o conceito ( $\mathrm{n}^{\circ}$ 29, Quadro 1) em contraposição ao Código, mas pode gerar dúvidas pelas diversas interpretações envolvidas no termo "interface entre ambientes terrestres e aquáticos" e pelo termo "solo hídrico" ser pouco usual no Brasil. Já a definição de Esteves (1998) (nº 


\section{5, Quadro 1) inclui como tipos de AUs, tanto áreas encharcadas quanto} fitofisionomias.

Com base no Quadro 1, observa-se que o conceito de AUs inclui características comuns, onde as mais importantes são a presença de água e os tipos da vegetação e de solos e, secundariamente, a forma de relevo. Contudo, a formulação do conceito e os valores dados a esses aspectos explicam as divergências nas concepções e nos critérios de identificação.

\begin{tabular}{|c|c|}
\hline $\mathbf{N}^{\circ}$ & Definições \\
\hline \multicolumn{2}{|r|}{ Internacionais } \\
\hline 1 & $\begin{array}{l}\text { "Áreas suavizadas cobertas com águas rasas permanentes, temporárias ou } \\
\text { intermitentes. São denominadas por nomes como pântanos, brejos, turfeiras, } \\
\text { dentre outras. Lagos rasos e lagoas, geralmente com presença de vegetação } \\
\text { emergente de características próprias, estão incluídos na definição, mas as águas } \\
\text { permanentes de córregos perenes, reservatórios e lagos profundos não estão } \\
\text { incluídas. Também não abrangem áreas com água temporária que pouco ou nada } \\
\text { influenciam no desenvolvimento de vegetação em solos úmidos" (Shaw; Fredine, } \\
\text { 1956, p. 3). }\end{array}$ \\
\hline 2 & $\begin{array}{l}\text { Áreas de pântano, charco, turfa ou água, natural ou artificial, permanente ou } \\
\text { temporária, com água estagnada ou corrente, doce, salobra ou salgada, incluindo } \\
\text { áreas de água marítima com menos de seis metros de profundidade na maré baixa } \\
\text { (Convenção de Ramsar - Brasil, 1996). }\end{array}$ \\
\hline 3 & $\begin{array}{l}\text { Área dominada por plantas herbáceas específicas, que crescem principalmente } \\
\text { na superfície da água, apresentando partes aéreas e que resistem a ambientes } \\
\text { cuja quantidade de água é excessiva para a maioria das outras plantas terrestres } \\
\text { (Westlake; Kvet; Szczepanski, 1988). }\end{array}$ \\
\hline 4 & $\begin{array}{l}\text { Áreas inundadas ou saturadas por água superficial ou subterrânea com frequência e } \\
\text { duração suficientes para dar suporte e que, em circunstâncias normais, dão suporte } \\
\text { à prevalência de vegetação adaptada às condições de solos saturados (United } \\
\text { States, 1977). }\end{array}$ \\
\hline 5 & $\begin{array}{l}\text { Áreas de solos encharcados ou terrenos inundados de forma sazonal, intermitente } \\
\text { ou permanente, seja de origem natural ou não, doce ou salina, como solos } \\
\text { encharcados, alagados, meandros abandonados, lagos, pântanos, planícies } \\
\text { litorâneas, estuários, rios e seus tributários (Chiffings, 1977). }\end{array}$ \\
\hline 6 & $\begin{array}{l}\text { "Áreas de transição entre sistemas terrestres e aquáticos, onde o nível freático } \\
\text { está normalmente na ou próximo da superfície, ou onde a superfície está coberta } \\
\text { por águas rasas. [...] devem apresentar pelo menos um dos seguintes três atributos: } \\
\text { a) ao menos periodicamente, a superfície está coberta predominantemente por } \\
\text { hidrófitas; b) o substrato é formado predominantemente por solo hídrico não } \\
\text { drenado; c) o substrato não é formado por solo, mas está saturado ou coberto por } \\
\text { águas rasas em algum momento durante a estação de crescimento de cada ano" } \\
\text { (Cowardin et al., 1979, p. 3). }\end{array}$ \\
\hline
\end{tabular}




\begin{tabular}{|c|c|}
\hline 7 & $\begin{array}{l}\text { Áreas que apresentam predomínio de solos hídricos e que são inundadas ou } \\
\text { saturadas de água superficial ou subterrânea, com frequência e duração suficientes } \\
\text { para determinar e que em circunstâncias normais determinam a prevalência de uma } \\
\text { vegetação hidrófila tipicamente adaptada às condições de solo saturado (United } \\
\text { States, 1985). }\end{array}$ \\
\hline 8 & $\begin{array}{l}\text { Unidades ecossistêmicas funcionais que apresentam, em termos espaço- } \\
\text { temporais, uma anomalia hídrica positiva em relação às áreas adjacentes. A } \\
\text { confluência de fatores topográficos, geológicos e hidrológicos faz com que esta } \\
\text { anomalia hídrica afete e condicione os processos geoquímicos e biológicos da área } \\
\text { em questão (Cataluña, 1985). }\end{array}$ \\
\hline 9 & $\begin{array}{l}\text { Terrenos permanente ou temporariamente cobertos por água ou encharcados. AUs } \\
\text { temporárias precisam ter água na superfície ou encharcamento com frequência e/ } \\
\text { ou duração suficientes para afetar a biota (Paijmans et al., 1985). }\end{array}$ \\
\hline 10 & $\begin{array}{l}\text { Terreno que apresenta nível d'água subterrâneo na superfície, próximo ou acima } \\
\text { dela, ou que está saturado por um período de tempo suficiente para promover áreas } \\
\text { úmidas ou processos aquáticos, como indicados por solos hídricos, vegetação } \\
\text { hidrófila, e vários tipos de atividades biológicas típicas de ambientes úmidos } \\
\text { (Zoltai, 1988). }\end{array}$ \\
\hline 11 & $\begin{array}{l}\text { Terreno saturado o suficiente para promover áreas úmidas ou processos aquáticos, } \\
\text { como indicados pela presença de solos mal drenados, vegetação hidrófila e por } \\
\text { vários tipos de atividades biológicas típicas de ambientes úmidos (Tarnocai et al., } \\
\text { 1988). }\end{array}$ \\
\hline 12 & $\begin{array}{l}\text { As áreas úmidas são terras, exploradas ou não, geralmente inundadas ou } \\
\text { encharcadas/saturadas por água doce, salgada ou salobra, de forma permanente } \\
\text { ou temporária; a vegetação, quando existente, é dominada por plantas higrófilas } \\
\text { durante, ao menos, uma parte do ano (France, 1992). }\end{array}$ \\
\hline 13 & $\begin{array}{l}\text { "As áreas úmidas são caracterizadas pela presença, permanente ou temporária, } \\
\text { de água superficial ou subsuperficial, doce, salobra ou salgada, muitas vezes em } \\
\text { posição de transição entre ambientes terrestres e aquáticos, sendo marcadas } \\
\text { por águas rasas, solos hidromórficos ou solos pouco desenvolvidos, e/ou uma } \\
\text { vegetação onde predominam plantas higrófilas ao menos durante uma parte do ano. } \\
\text { [...]. Elas estão localizadas à beira de nascentes, córregos, rios, lagos e marés, em } \\
\text { baías e estuários, dentro de deltas, fundos de vales ou depressões em encostas" } \\
\text { (0. Cizel, 2010, p. 12). }\end{array}$ \\
\hline 14 & $\begin{array}{l}\text { “[...] sistemas de extensão sub-regional onde a presença espacial e temporal da } \\
\text { água provoca fluxos biogeoquímicos característicos, solos com hidromorfismo } \\
\text { acentuado e uma biota cuja estrutura e dinâmica está bem adaptada a uma vasta } \\
\text { variabilidade de disponibilidade de água. Podem ser consideradas macrossistemas } \\
\text { cuja complexidade cresce com a variabilidade hidrossedimentológica e a extensão } \\
\text { geográfica" (Neiff; Iriondo; Caragnan, 1994, p. 2). }\end{array}$ \\
\hline 15 & $\begin{array}{l}\text { "Ecossistemas que dependem de inundações rasas ou de saturação do substrato } \\
\text { de forma constante ou recorrente na ou próximo da superfície. As características } \\
\text { mínimas essenciais são inundação ou saturação recorrente na ou próximo da } \\
\text { superfície e presença de características físicas, químicas e biológicas que refletem } \\
\text { inundação ou saturação recorrente do substrato. Indicadores típicos no diagnóstico } \\
\text { de Áreas Úmidas são solos hídricos e vegetação hidrófila. Estes indicadores estarão } \\
\text { presentes exceto onde fatores físico-químicos, bióticos ou antrópicos específicos } \\
\text { tenham sido removidos ou impedido o seu desenvolvimento" (NRC, 1995, p. 59). }\end{array}$ \\
\hline
\end{tabular}




\begin{tabular}{|c|c|}
\hline 16 & $\begin{array}{l}\text { Terreno de transição entre sistemas terrestres e aquáticos, onde o nível d'água está } \\
\text { geralmente na ou próximo da superfície, ou o terreno é coberto periodicamente por } \\
\text { águas rasas, e que em circunstâncias normais mantém ou manteria uma vegetação } \\
\text { tipicamente adaptada às condições de solo saturado (South African, 1998). }\end{array}$ \\
\hline 17 & $\begin{array}{l}\text { Áreas onde a água cobre o solo durante todo o ano, ou em apenas algumas épocas } \\
\text { do ano. Incluem pântanos, brejos, meandros abandonados, lagos, lagoas, pântanos } \\
\text { salinos, lamaçais, mangues, recifes de corais, charcos e turfeiras. As AUs podem } \\
\text { ser naturais ou artificiais, com águas estagnadas ou correntes, doces, salobras ou } \\
\text { salinas. Há também AUs subterrâneas (Australian Government, [2017?]). }\end{array}$ \\
\hline 18 & $\begin{array}{l}\text { "Qualquer superfície do terreno temporária ou permanentemente encharcada ou } \\
\text { inundada, natural ou artificial, com água estagnada ou corrente, variando de doce } \\
\text { à salina, e onde as inundações influenciam a biota e os processos ecológicos a } \\
\text { qualquer momento" (Boulton; Brock,1999, p. 3). }\end{array}$ \\
\hline 19 & $\begin{array}{l}\text { “Uma AU é um ecossistema ou unidade funcional de caráter predominantemente } \\
\text { aquático, que não sendo um rio, nem um lago, nem ambiente marinho, constitui, } \\
\text { no espaço e no tempo, uma anomalia hídrica positiva em relação a um entorno } \\
\text { mais seco. A conjunção hierárquica de fatores climáticos e hidrogeomorfológicos } \\
\text { gera inundações rasas recorrentes, permanentes, sazonais ou irregulares, e/ } \\
\text { ou condições de saturação na ou próximo da superfície do terreno pela presença } \\
\text { de águas subterrâneas, suficientemente importantes para afetar os processos } \\
\text { biogeofisicoquímicos da região em questão. A característica essencial mínima para } \\
\text { diagnosticar a existência de uma AU é a inundação por águas rasas superficiais } \\
\text { (formação palustre) ou saturação na ou da superfície do terreno (solos úmidos), } \\
\text { condicionando outras características fundamentais de apoio ao diagnóstico, que } \\
\text { são a presença de solos hídricos e/ou a vegetação higrófila. Geralmente, essas } \\
\text { propriedades explicam a existência de comunidades especiais de microorganismos } \\
\text { e de fauna, assim como diferentes atividades humanas e uma paisagem com grau } \\
\text { elevado de qualidade visual em relação ao entorno" (Gil, 2002, p. 81). }\end{array}$ \\
\hline 20 & $\begin{array}{l}\text { "A definição geralmente inclui três componentes principais (1) as AUs são } \\
\text { distinguidas pela presença de água, quer na superfície ou na zona de raízes; (2) as } \\
\text { AUs geralmente apresentam condições únicas de solo, que diferem de entornos } \\
\text { mais elevados; (3) as AUs mantém uma biota, tal como uma vegetação adaptada às } \\
\text { condições úmidas (hidrófitas) [...]" (Mitsch; Gosselink, 2007, p. 27). }\end{array}$ \\
\hline 21 & $\begin{array}{l}\text { "Uma AU pode ser descrita como uma mistura de características de ambientes } \\
\text { terrestres ou aquáticos. Em essência, uma AU é a borda ou interface entre as terras } \\
\text { altas e as áreas aquáticas adjacentes. A água pode estar na forma de rios, córregos, } \\
\text { riachos, lagos, pontos de exfiltração ou ser do oceano. Assim, as AUs podem ser } \\
\text { encontradas em praticamente qualquer lugar. Elas possuem características de } \\
\text { ambos os ambientes e exibem uma mistura de condições de solo, planta e água, } \\
\text { que cria um habitat único para a vida e seus processos. As AUs podem ser de difícil } \\
\text { identificação em função das diversas combinações que podem apresentar ao longo } \\
\text { do gradiente entre o meio terrestre e aquático" (Lyon; Lyon, 2011, p. 9). }\end{array}$ \\
\hline 22 & $\begin{array}{l}\text { "Ecossistemas que surgem quando a inundação produz solos com predomínio de } \\
\text { processos anaeróbicos, que, por sua vez, força a biota, particularmente as plantas } \\
\text { enraizadas, a se adaptar à inundação" (Keddy, 2010, p. 3). }\end{array}$ \\
\hline
\end{tabular}




\begin{tabular}{|c|c|}
\hline 23 & $\begin{array}{l}\text { "As AUs geralmente apresentam quatro características: (1) águas rasas na } \\
\text { superfície ou na zona de raízes, em pelo menos alguma parte do tempo; (2) } \\
\text { dinâmica lenta da água ou águas estagnadas; (3) solos inundados ou encharcados } \\
\text { sob processos de redução ou, pelo menos, anaeróbicos; (4) vegetação adaptada } \\
\text { às condições de encharcamento e/ou inundação. Plantas não tolerantes a estas } \\
\text { condições são praticamente ausentes. Plantas adaptadas às condições úmidas, } \\
\text { designadas por hidrófitas, podem ser emergentes ou submersas" (Paul, 2013, p. } \\
\text { 73). }\end{array}$ \\
\hline \multicolumn{2}{|r|}{ Nacionais } \\
\hline 24 & $\begin{array}{l}\text { Áreas episodicamente ou periodicamente inundadas pelo transbordamento lateral } \\
\text { de rios ou lagos e/ou pela precipitação direta ou pelo afloramento do lençol freático, } \\
\text { de forma que a biota responde ao ambiente físico-químico com adaptações } \\
\text { morfológicas, anatômicas, fisiológicas e etológicas, gerando estruturas específicas } \\
\text { e características dessas comunidades (Junk; Bayley; Sparks, 1989). }\end{array}$ \\
\hline 25 & $\begin{array}{l}\text { As AUs brasileiras podem ser definidas como zonas nas quais a vegetação } \\
\text { ocorrente é tolerante ou adaptada a solos úmidos ou a solos que são alagados diária } \\
\text { ou sazonalmente. Esses ecossistemas brasileiros podem ser divididos em quatro } \\
\text { grupos: 1) áreas úmidas formadas por planícies inundadas de sistemas fluviais } \\
\text { (várzea, igapó, pantanal, etc.); 2) áreas úmidas associadas a lagoas e lagos (brejos, } \\
\text { zonas litorâneas etc.); 3) áreas úmidas com altos níveis de saturação hídrica e/ou } \\
\text { acúmulo de águas de córregos (brejo, pântano, campo úmido, lameiro etc.); 4) áreas } \\
\text { úmidas artificiais (represas, açudes e barramentos) (Esteves, 1998). }\end{array}$ \\
\hline 26 & $\begin{array}{l}\text { Segmento da paisagem constituído por solos hidromórficos, definidos como aqueles } \\
\text { que em condições naturais se encontram saturados por água, permanentemente } \\
\text { ou em determinado período do ano, independentemente de sua drenagem atual e } \\
\text { que, em virtude do processo de sua formação, apresentam, comumente, dentro } \\
\text { de } 50 \text { (cinquenta) centímetros a partir da superfície, cores acinzentadas, azuladas } \\
\text { ou esverdeadas e/ou cores pretas resultantes do acúmulo de matéria orgânica } \\
\text { (Paraná, 2008). }\end{array}$ \\
\hline 27 & $\begin{array}{l}\text { Pantanais e superfícies terrestres cobertas de forma periódica por águas, cobertas } \\
\text { originalmente por florestas ou outras formas de vegetação adaptadas à inundação } \\
\text { (Brasil, 2012). }\end{array}$ \\
\hline 28 & $\begin{array}{l}\text { Pantanais e as superfícies terrestres inundadas naturalmente e de forma periódica, } \\
\text { cobertas originalmente por florestas ou outras formas de vegetação adaptadas à } \\
\text { inundação (Minas Gerais, 2013). }\end{array}$ \\
\hline 29 & $\begin{array}{l}\text { "Ecossistemas na interface entre ambientes terrestres e aquáticos, continentais ou } \\
\text { costeiros, naturais ou artificiais, permanentemente ou periodicamente inundados } \\
\text { por águas rasas ou com solos encharcados, doces, salobras ou salgadas, com } \\
\text { comunidades de plantas e animais adaptadas à sua dinâmica hídrica. AUs devem } \\
\text { possuir (1) presença, pelo menos periodicamente, de espécies de plantas superiores } \\
\text { aquáticas ou palustres, e/ou (2) presença de substrato/solo hídrico" (Junk et al., } \\
2014, \text { p. 23; Cunha; Piedade; Junk, 2015, p. 37). }\end{array}$ \\
\hline
\end{tabular}




\begin{tabular}{|l|l|}
\hline 30 & "Ambientes transicionais ou de interface entre os ambientes aquáticos e terrestres. \\
Incluem todos os ecossistemas transicionais entre os ambientes aquáticos e \\
terrestres, naturais ou artificiais, associados ao ciclo das águas interiores e \\
costeiras, com o nível de água variável ou relativamente estável ao longo do tempo, \\
cujos solos apresentam elevado grau de hidromorfismo, condicionados por águas \\
de origem pluvial, fluvial, marinha, subterrânea ou de combinações entre elas, com \\
contribuição de marés ou não, com comunidades de plantas e animais adaptadas à \\
dinâmica hídrica" (Queiroz, 2015, p. 60).
\end{tabular}

Quadro 1 - Síntese com os principais conceitos de AUs

Fonte: Gomes (2017, p.51).

\section{Considerações sobre as AUs sob a ótica dos entrevistados}

Os fatores hidrogeomorfológicos foram determinantes em todas as respostas, enquanto algumas incluíram aspectos relacionados ao substrato, à vegetação e/ou ao clima.

Os fatores determinantes seriam o relevo e a hidrológico/climatológico, que vão condicionar a existência, [...] mas o clima no sentido mais amplo. Onde tem relevo muito íngreme, se tiver áreas de depressão é possível ter AUs. [...]. Pode ter fatores antrópicos, que podem ou não ser fundamentais. Quando você cria uma represa, por exemplo, você pode criar ao redor do reservatório AUs que não existiam. Talvez antes não tinha AUs, mesmo tendo um rio e um relevo lá. (Entrevistado 1).

A forma do relevo e a fonte de água determinam. O solo é coadjuvante, mas vai influenciar o tempo necessário da permanência da água. O clima está em uma outra escala, a disponibilidade de água é uma função do clima. (Entrevistado 2).

A topografia do terreno e o afloramento do lençol freático determinam a formação das áreas úmidas, [...] mas pode ter por acúmulo de água pluvial na topografia. A vegetação e o tipo de solo podem influenciar na formação [...], mas antes para mim vem a topografia, que é condicionante de terreno. (Entrevistado 3).

[...] as condições de não escoamento da água, uma retenção dessa água pelo menos um período do ano e as condições de relevo. (Entrevistado 4). 
Presença de água, existência de uma comunidade e espécies adaptadas a esse sistema e um solo que permita o acúmulo de água, pelo menos uma parte do ano. Um relevo que facilite acumulação e um sistema de água que permita ela ocorrer. Uma planície de inundação, por exemplo, a formação de AUs tem a ver com a possibilidade de extravasamento da água, quer dizer, não é a profundidade do rio que define se forma ou não uma $\mathrm{AU}$ e sim o relevo adjacente. (Entrevistado 5).

Em termos dos critérios para a definição, foram mencionados aqueles associados à presença da água, ao tipo de vegetação e as características do substrato presentes. As respostas variaram desde aqueles onde é necessário apenas um critério, até os que incluem os três, a presença de água, espécies adaptadas e solo hidromórfico. A necessidade do solo hidromórfico foi questionada por alguns entrevistados em função do tempo de formação ser relativamente maior que de uma AU, ou por ser um possível resquício de um paleoambiente e/ou porque AUs podem ter substratos rochosos ou sedimentos. A maioria dos entrevistados convergiu que é necessária a presença de uma umidade mínima durante um tempo mínimo, variável com as características locais de cada região, para influenciar o tipo de vegetação.

A Figura 1 gerou maiores divergências entre os entrevistados, pois ao mesmo tempo que pode ser classificada como uma AU em função da forma côncava e da presença de água, provoca dúvidas pelo tipo de solo e da pluviosidade passageira. Na Figura 2 foi considerada como AU a área dentro do canal e seu entorno. 


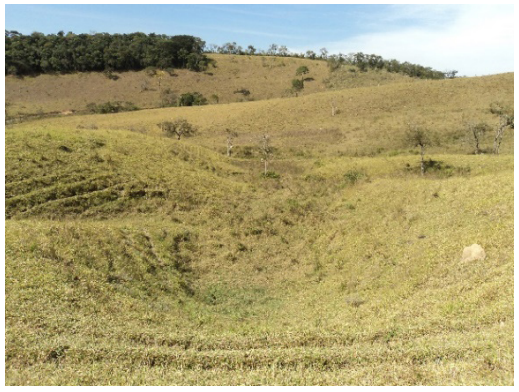

Figura 1 - Zona de cabeceira dedrenagem, temporariamente saturada, chuvas efêmeras e solos argilosos

Fonte: GOMES (2017, p.143).

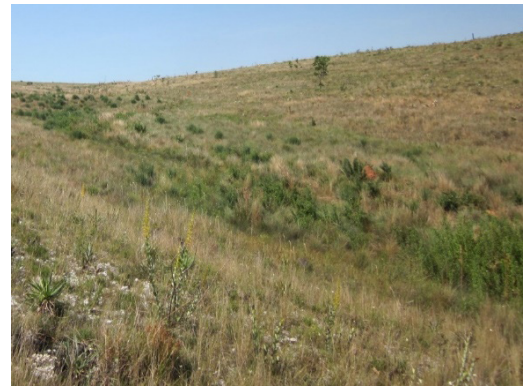

Figura 2 - Canal de pequena ordem, brejo temporário no entorno, solo acinzentado e plantas adaptadas a ambientes úmidos

Fonte: Gomes (2017, p. 144).

Em relação às AUs como ambientes de transição/interface entre sistemas aquáticos e terrestres, somente um entrevistado considerou AUs como ecossistemas aquáticos. Os outros entrevistados convergem ao considerar que as AUs são conceitualmente sistemas de interface, mas essa ideia pode estar sujeita a diversas interpretações, pois assim como na literatura, envolve dimensões espaciais, temporais, espaço-temporais e/ou outros:

Quando se fala em interface normalmente o mais comum é a interface terrestre e o sistema aquático, como na zona litorânea que pode ter bastante AUs e no caso dos sistemas de planícies de inundação também, onde tem um rio que pode alimentar diversos lagos e esses vão ter áreas de interface que são pulsantes. [...]. Pode ser espacial e temporal, geralmente isso acontece quando tem um corpo d'água por perto, estou movimentando no tempo entre uma AU e a área seca. [...] Também pode ter um lençol que sobe e dá origem a uma AU..., quando o lençol baixar essa AU pode secar. Posso ver isso como uma interface temporal. [...]. Pode acontecer também em sistemas que originados pela água da chuva..., não tem um sistema aquático que dá origem, que é a origem da água. [...]. Conceitualmente, a AU é uma interface entre aquático e terrestre, é importante isso ser notado, ela não é nem um sistema terrestre e nem um sistema aquático. [...] O pântano é um bom exemplo, ele está sempre lá, não é pulsante, mas sabemos que não é um lago, mas também não é terrestre. Lá existe um ecossistema que corresponde a ele, esse é um critério muito importante. Tem uma vegetação e 
animais adaptados a esse sistema, que não é nem aquática e nem terrestre. (Entrevistado 1).

Eu prefiro enxergar todo o ambiente aquático, inclusive o transicional, como um ambiente úmido, porque é um sistema só do ponto de vista do funcionamento da dinâmica. A convenção de Ramsar estabelece 6 metros de profundidade, [...] propôs-se um conceito pensando na gestão de quais ambientes administrar. Esse corte foi feito para os ambientes marinhos e não continentais. (Entrevistado 2).

São áreas em transição entre estes dois ambientes, envolvendo fatores bióticos e abióticos de ambos ecossistemas. [...] não são ambientes aquáticos, que tem uma fauna e flora mais característica em resposta também aos fatores abióticos; e nem terrestres, que igualmente tem características diferentes (Entrevistado 3).

Pode ser a interface espacial e temporal. Não necessariamente precisa estar sempre entre o ambiente aquático e terrestre. [...] Não precisa ser sempre ecótono. Ela tem os dois elementos, mas não é só. Ela pode ser mais aquática do que só da transição. [...] Ela pode estar em ambientes que tem espécies que colonizam em ambientes de AUs totalmente alagados durante maior parte do ano ou ano inteiro e existem aquelas que são exatamente colonizadoras de ambientes com umidade um certo período do ano e mais seco em outro período. (Entrevistado 4).

Essa transição é espacial, mas na verdade ela é as duas coisas, ela ocorre no tempo e no espaço. [...] Elas crescem e diminuem em função da disponibilidade de água naquele sistema, ao longo do tempo. [...] A AU é a transição, é a área de interface. A AU é um ecossistema também. Ela não é um rio, um tipo de ecossistema; e nem uma área seca, outro tipo de ecossistema. Ela é uma AU, como se fosse um ecótono entre os dois sistemas, mas com espécies próprias, formando um ecossistema único. [...] você pode ter AU pluvial ou por água subterrânea e é uma transição, transicionou aquele ambiente que era terrestre para um aquático. [...] Não precisa ter conectividade com ecossistema aquático. (Entrevistado 5).

A escala é uma das questões mais relevantes, pois dependendo do recorte espacial, as AUs podem incluir corpos d'água e/ou terras secas. Todos os entrevistados consideraram que a Figura 3 é uma AU e a Figura 4, dependendo da escala, é uma AU ou incorpora AUs. 


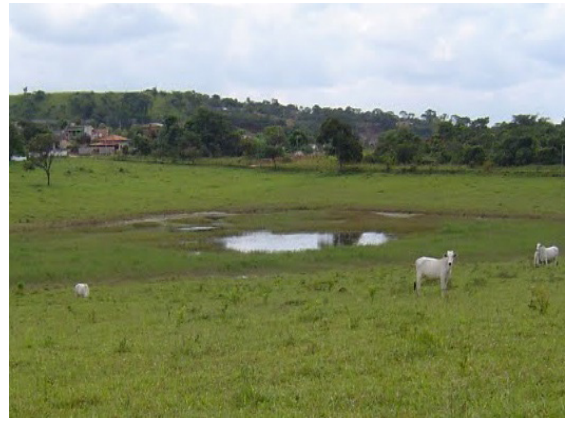

Figura 3 - Dolina, sem conexão com 0 lençol freático profundo, solo mal drenado e encharcado temporariamente pela chuva

Fonte: Gomes (2017, p.152).

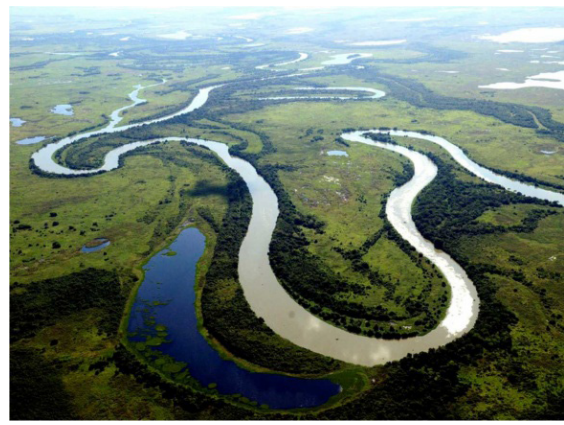

Figura 4 - Lagoas marginais permanentes ou temporárias e vegetação adaptada a ambientes úmidos e aquáticos

Fonte: Disponível em: $<<$ http://planetaagora. blogspot.com.br/2014/02/2-de-fevereiro-dia-mundialdas-zonas.html> Acesso em: 23 jun. 2017.

Considerar determinados corpos d'água como AUs é um desafio, pois, dependendo do tipo e de suas características, as AUs podem se comportar como corpos d'água, ao menos uma parte do tempo. Assim, não há como definir um limite de profundidade, velocidade e tempo de permanência da água para determinar se é ou não uma AU. Alguns entrevistados ainda ressaltaram que depende das características das espécies que irão colonizar o ambiente:

Têm corpos d'água que podemos considerar como permanentes e têm outros que são interface entre o corpo d'água permanente e o continente e vão ter funções ecológicas claramente definidas [...]. Vou pegar, por exemplo, as áreas de mangue [...]. Tem água permanente, a velocidade da água vai variar com muita frequência. Em algum momento do dia vai ter muita velocidade, em outros estará parada. Como isso ocorre diariamente, estou usando como exemplo. Nesse caso é uma AU, é um corpo d'água que é dentro da AU. Nesse sentido pode ter corpo d'água dentro de AU. No Pantanal, por exemplo, posso até ter canais que podem fluir para os dois lados. Às vezes estão cheios de água, com 3 metros dentro, e correm bastante. Esses canais fazem parte da AU. O rio Cuiabá e Paraguai não são AUs, eles que vão encher esses canais por 4 ou 5 meses, eles são sistemas aquáticos fundamentais. [...]. Mas depende muito da escala que estamos olhando. O ecossistema Pantanal, ele todo 
é uma AU, mesmo passando um rio dentro. Aí, a escala é muito importante. Tem que ter flexibilidade na hora de olhar. [...]. Por exemplo, esse sistema de dolinas (Figura 3) preenchidas por água pluvial fazem parte da AU porque não é um ecossistema aquático que constitui a interface e não é o lençol freático [...]. Agora, em alguns anos você pode ter sistemas puramente aquáticos. Enche de água, se aproxima da beira deles e se eles são suficientemente grandes, vão gerar uma zona de interface. Mas quando são bem rasos são todos AUs. [....]. Para mim,uma característica clara das AUs, não um fator determinante, é que muitas vezes têm uma evolução rápida. (Entrevistado 1).

Um ambiente fechado, lacustre, por exemplo, eu falaria que se ele for de pequeno tamanho e tender a evaporar e diminuir muito a sua lâmina d'água, eu consideraria uma AU. Mas se for mais estável e maior em termos de tamanho, eu chamaria de lago. Um lago, que tivesse pouca variação no nível da água, eu consideraria AU até onde há plantas anfíbias propriamente ditas... porque é muito difícil, não dá para dizer de altura e de velocidade porque isso varia com a luminosidade, com o tipo de planta, estrutura do solo. (Entrevistado 3).

Eu englobaria os corpos d'água aos ecossistemas das AUs, como nas veredas, [...] também incluiria as áreas secas nos campos de murundus, [...] fazem parte de seus ecossistemas. [...]. Para vegetação tem um limite da lâmina d'água para espécies, por exemplo, que são enraizadas. Tem um gradiente até onde ela consegue se enraizar e tem uma haste onde ela vai ultrapassar o nível d’água. Mas existem outras espécies que são flutuantes [...] e outras submersas [...].Também temos alguns exemplos de espécies que colonizam áreas de corredeiras, isso não é um impedimento. Desde águas mais paradas até cachoeiras. É claro que você vai diminuir espécies que são adaptadas a essas condições. (Entrevistado 4).

Eu não acho que rio, lago e lagoa sejam AUs, mas são parte de um ecossistema que compõem as AUs [...] porque nesse caso particular você está falando de escala né. [...]. O rio é uma coisa, está lá, é um ambiente em si, mas sua interface com a área adjacente é o que gente classificaria como AU. [...]. Porque, para mim, a AU é um ambiente que oferece disponibilidade, oportunidade para as espécies viverem lá. [...] A bacia do Paraguai é o ecossistema do Pantanal, uma AU. Dentro desse ecossistema tem AUs, rios, áreas de nascente, áreas terrestres, que são sistemas diferentes, mas que formam parte dessa 
bacia. [...] Dentro da vereda você tem AUs e o rio, ou seja, tem ambiente aquático dentro, [...], que não é AU. Agora ele é parte de um ecossistema maior que se chama vereda, que tem uma escala própria, e a vereda tem vários tipos de AUs, o rio está alinhado dentro da vereda, mas o rio é o rio, tem legislação especifica para ele, enquanto a AU não. (Entrevistado 5).

Por fim, a delimitação das AUs é considerada a questão mais complexa e que para fins de proteção ainda inclui, segundo alguns entrevistados, os serviços ambientais fornecidos e as áreas que contribuem para sua manutenção hidrológica.

\section{Proposta Conceitual de Áreas Úmidas}

O Quadro 2 apresenta uma síntese do papel dos fatores hidrológicos, pedológicos, vegetacionais, geomorfológicos e das escalas espaço-temporais na formação, definição, identificação e delimitação das AUs.

\begin{tabular}{|c|c|}
\hline Água & $\begin{array}{l}\text { As AUs podem ou não apresentar lâmina d'água. Quando existente, } \\
\text { geralmente são rasas, mas não há como estabelecer limites em termos de } \\
\text { profundidade e dinâmica. A umidade do substrato pode ser variável, mas } \\
\text { está na ou próxima da superfície e é suficiente para imprimir processos } \\
\text { e características típicas de AUs. A diferença entre corpos d'água e AUs } \\
\text { está nas características e funções ecológicas desempenhadas pelos } \\
\text { ecossistemas. }\end{array}$ \\
\hline Vegetação & $\begin{array}{l}\text { As espécies vegetais são anfíbias e/ou macrófitas aquáticas. Sua } \\
\text { presença não precisa ser permanente ou obrigatória, variando conforme } \\
\text { as características do regime hidroclimático e do substrato. Além disso, } \\
\text { quando somente o critério de vegetação se faz presente como indicativo } \\
\text { de AUs, a sua retirada pode vir a ser estimulada, podendo ou não } \\
\text { desconfigurar uma AU. }\end{array}$ \\
\hline Solo & $\begin{array}{l}\text { Solos hidromórficos nem sempre indicam uma AU, pois há AUs formadas } \\
\text { em substratos rochosos ou sedimentos, há AUs cujos solos estão em } \\
\text { estágios iniciais de formação e há solos hidromórficos que representam } \\
\text { paleoambientes. }\end{array}$ \\
\hline Relevo & $\begin{array}{l}\text { As AUs ocorrem em relevos que permitem um maior acúmulo de água, } \\
\text { como planícies de inundação, depressões e cabeceiras de drenagem. } 0 \\
\text { relevo auxilia na compreensão do funcionamento hidrológico, na localização } \\
\text { e delimitação das AUs na paisagem. }\end{array}$ \\
\hline Escala & $\begin{array}{l}\text { A escala é fundamental na identificação e delimitação das AUs, pois, } \\
\text { dependendo do recorte analisado, as AUs podem incluir corpos d'água e/ou } \\
\text { áreas secas. Além disso, junto com a hidrogeomorfologia, permite avaliar o } \\
\text { seu comportamento e funcionamento hidrológico. }\end{array}$ \\
\hline
\end{tabular}




\begin{tabular}{|c|c|}
\hline Interface & $\begin{array}{c}\text { As AUs podem apresentar diversos "tipos de interface", como espacial, } \\
\text { temporal, espaço-temporal, sistema nem terrestre e nem aquático, } \\
\text { sistema com características de ambientes terrestres e aquáticos, ecótono, } \\
\text { ecossistema único e até alternativas. }\end{array}$ \\
Quadro 2 - Principais questões referentes às AUs
\end{tabular}

Fonte: Adaptado de Gomes (2017).

Diante do exposto, foi elaborada a seguinte proposta conceitual de AUs:

Áreas Úmidas (AUs) são sistemas permanentes ou temporariamente saturados, inundados e/ou alagados, formados em relevos e substratos que permitem um maior acúmulo de águas superficiais e/ou subsuperficiais, por tempo suficiente para promover processos físicos, químicos e biológicos de ambientes com deficiência ou ausência de oxigênio, indicados, comumente, por espécies vegetais adaptadas a essas condições e/ou por solos com características hidromórficas. Interferências antrópicas podem condicionar a sua formação, como as AUs em áreas marginais de reservatórios. Conforme a escala de análise da dinâmica hidrológica, as AUs podem incluir áreas permanentemente secas e/ou aquáticas, que são fundamentais para a sua manutenção ecológica (Gomes, 2017, p. 166).

\section{Considerações Finais}

Apesar do aumento das pesquisas relacionadas às AUs brasileiras ainda há muitas divergências quanto aos critérios de definição que, por sua vez, comprometem os processos para proteção e gestão sustentável desses sistemas de grande relevância socioambiental. Os debates de caráter multidisciplinar precisam ser fomentados para se chegar à construção de uma estrutura conceitual comum entre os campos de conhecimento envolvidos, que deverá englobar as características que assumem papel central na definição e nos processos de caracterização das AUs. É o caso das questões relativas à identificação e delimitação das AUs, a sua diferenciação de ecossistemas aquáticos e ecossistemas terrestres, à busca de abrangência capaz de englobar os diferentes contextos geomorfológicos e os diferentes tipos de AUs, e à operacionalização dos conceitos nos aparatos de gestão.

A proposta conceitual, construída a partir de pesquisas bibliográficas e entrevistas com especialistas, foi uma tentativa de reduzir 
as diversas discordâncias e ambiguidades existentes na concepção e caracterização das AUs e permitir um maior entendimento e aplicação do conceito. Nesse sentido, a proposta apresentada se insere nesse contexto de busca de avanços nas discussões sobre um referencial conceitual que possa ser aplicado nacionalmente por gestores, técnicos, pesquisadores e pela sociedade, em geral.

\section{Notas}

1 Entrevistas semiestruturadas são guiadas por um roteiro flexível, que permite maior interação entrevistador/entrevistado e uma cobertura mais densa e ampla do tema (Boni; Quaresma, 2005).

20 método de análise de conteúdo utiliza um conjunto de técnicas e procedimentos sistemáticos, que permite a organização dos dados para descrever o conteúdo de entrevistas e obter indicadores, sejam eles quantitativos ou não, para interpretações e possíveis inferências de conhecimentos. Dentro da AC, a técnica de análise categorial desmembra os textos em unidades, de acordo com categorias estabelecidas (Bardin, 2008).

3 USFWS - Serviço Estadunidense de Pesca e Vida Silvestre.

4 NRC - Serviço de Conservação dos Recursos Naturais.

5 Hidrófitas: plantas que vivem em ambientes muito úmidos, mas não são aquáticas.

6 Solos hídricos: solos que se encontram permanentemente ou temporariamente saturados por água, resultando em condições anaeróbicas (Reddy; Delaune, 2008).

7 Ecótonos são zonas de transição e tensão entre duas comunidades, o que implica em valores intermediários de densidade, cobertura e volume e que ambas as comunidades interferem umas sobre as outras (Neiff, 2003). Dentro das planícies de inundação podem existir ecótonos locais, mas como um todo, a planície é um sistema próprio. Conforme Tiner (1999), o conceito ecótono seria aplicado de forma mais correta a comunidades individuais de plantas do que a tipos de "habitats" amplos e vastos, como podem ser as AUs.

8 INAU - Instituto Nacional de Áreas Úmidas.

\section{Referências}

AUSTRALIAN GOVERNMENT. Department of the Environment and Energy. About Wetlands.What are wetlands? [2017?]. Disponível em: <http://www. environment.gov.au/water/wetlands/about>. Acesso em: 01 mar. 2017.

BARBIER, E. B.;ACREMAN, M. C; KNOWLER, D. Economic valuation of wetlands: A guide for policy makers and planners.1. ed. Switzerland: Ramsar Convention Bureau, 1997. Disponível em: < https://www.researchgate.net/ publication/246010067_Economic_valuation_of_wetlands_a_guide_for_policy_ makers_and_planners $>$. Acesso em: 05 maio2017. 
BARDIN, L. Análise de conteúdo. 4. ed. Lisboa: Edições 70, 2008. 223 p.

BOULTON, A. J.; BROCK, M. A. Australian Freshwater Ecology: Processes and Management. Gleneagles Publishing: Adelaide. 1999, 300p.

BONI, V.; QUARESMA, S. J. Aprendendo a entrevistar: como fazer entrevistas em Ciências Sociais. Revista Eletrônica dos Pós-Graduandos em Sociologia Política da UFSC, Florianópolis, v. 2, n. 1, p. 68-80. 2005. Disponível em: < https://periodicos.ufsc.br/index.php/emtese/article/viewFile/18027/16976>. Acesso em: 05 ago. 2015.

BRASIL. Decreto $n^{0}$ 1.905, de 16 de maio de 1996. Promulga a Convenção sobre Zonas Úmidas de Importância Internacional, especialmente como Habitat de Aves Aquáticas, conhecida como Convenção de Ramsar, de 02 de fevereiro de 1971. Diário Oficial da República Federativa do Brasil, Brasília, DF, 17 maio 1996.

BRASIL. Lei $\mathrm{n}^{0}$ 12.651, de 25 de maio de 2012. Dispõe sobre a proteção da vegetação nativa e dá outras providências. Diário Oficial da República Federativa do Brasil, Brasília, DF, 28 maio 2012.

CATALUÑA (Comunidad autónoma española). Ley 12/1985, de 13 de junio, de Espacios Naturales. Fecha Publicación DOGC 30/11/1994.

CHIFFINGS, A.W. An inventory of research and available information on wetlands in Western Australia. Dept. of Conservation and Environment, Wetlands Advisory Committee. 1977. Disponível em: < https://library.dpaw.wa.gov. au/static/FullTextFiles/004047.e.pdf> Acesso em: 10 ago. 2015.

COWARDIN, L. M, et al. Classification of wetlands and deepwater habitats of the United States. US Department of the Interior. Fish and Wildlife Service. Washington, DC. Office of Biological Services. FWS/OBS-79/31. Dez. 1979.

CUNHA, C. N.; PIEDADE, M. T. F.; JUNK, W. J. Classificação e delineamento das áreas úmidas brasileiras e de seus macrohabitats. Cuiabá: EdUFMT, 2015. 165 p. Disponível em <http://cppantanal.org.br/wp-content/uploads/2017/04/E-bookClassificacao-e-Delineamento-das-AUs.pdf> Acesso em: 02 fev. 2015.

UNITED STATES. Clean Water Act, Section 404, 1977. Establishes a program to regulate the discharge of dredged or fill material into waters of the United States, including wetlands. U.S Army Corps of Engineers: U.S. Environmental Protection Agency.1977. Disponível em: <https://www.epa.gov/cwa-404/clean-wateract-section-404>. Acesso em: 23 mar. 2015.

. Food Security Act of 1985 (P.L. 99-198). Provides a 5-year framework for the Secretary of Agriculture to administer various agriculture and food programs. United States Department of Agriculture.1985. Disponível em: <https:// www.ers.usda.gov/webdocs/publications/41995/15133_aib498_1_.pdf?v=41055>. Acesso em: 23 mar. 2015.

ESTEVES, F. A. Considerations on the ecology of wetlands, with emphasis on braziliam floodplain ecosystems. Oecologia Brasiliensis, Ecophysiological strategies of xerophytic and amphibious plants in the neotropics, Rio de Janeiro, v. 4, p. 111-135, 1998. 
FRANCE. Loi n 92-3 du 3 janvier 1992 sur l'eau. Consacre l'eau en tant que patrimoine commun de la Nation. 1992.

FINLAYSON, C. M; DAVIDSON, N. C. Global review of wetland resources and priorities for wetland inventory. Supervising Scientist. Supervising Scientist Report 144 / Wetlands International Publication 53, Canberra, 1999. Disponível em:<https://www.environment.gov.au/system/files/resources/b7be7f68-4522-4aa58e86-de5cabd21645/files/ssr144-full-report-web.pdf > Acesso em: 02 mar. 2017.

GOMES, C. S. Bases teórico-conceituais e subsídios para a classificação hidrogeomorfológica das áreas úmidas em Minas Gerais. 2017. 212 f. Dissertação (mestrado) - Departamento de Geografia - Universidade Federal de Minas Gerais, Belo Horizonte, 2017.

JUNK, W. J.; BAYLEY, P. B.; SPARKS, R. E. The Flood Pulse Concept in River Floodplain Systems. Canadian Journal of Fisheries and Aquatic Sciences, Special Publication, n.106, p. 110-127, 1989.

JUNK, W. J; et al. Definição e Classificação das Áreas Úmidas (AUs) Brasileiras: Base Científica para uma Nova Política de Proteção e Manejo Sustentável. In: Classificação e Delineamento das Áreas Úmidas Brasileiras e de seus Macrohabitats. Cuiabá: Ed UFMT. 2014. Disponível em: < http:/cppantanal.org. br/wp-content/uploads/2017/04/E-book-Classificacao-e-Delineamento-das-AUs. pdf >. Acesso em: 02 fev. 2015.

GIL, I. N. Plan Andaluz de Humedales: $10^{\circ}$ aniversario de la aprobación. Sevilha, Espanha: Junta de Andalucía,Consejería de Agricultura, Pesca y Medio Ambiente, 2002. 34p. Disponível em: <https://www.juntadeandalucia. es/medioambiente/portal web/servicios generales/doc tecnicos/publicaciones renpa/memoria_humedales_10_aniversario/10_aniversario_pah.pdf $>$. Acessō em: 12 abr. $201 \overline{6}$.

KEDDY, P.A. Wetland Ecology: Principles and Conservation. Cambridge University Press: Cambridge, IK, USA, 2010. 497p.

LEFOR, M. W.; KENNARD, W. C. Inland Wetland Definitions. Connecticut Institute ff Water Resource, Report n 28, nov. 1977. Disponível em: < http:/ opencommons.uconn.edu/cgi/viewcontent.cgi?article $=1026 \&$ context $=$ ctiwr specreports > Acesso em: 06 jun. 2017.

LYON, J. G.; LYON, L. K. Practical Handbook for Wetland Identification and Delineation, 2. ed. CRC Press. 2011. 189 p.

MINAS GERAIS (Estado). Lei Florestal Mineira $n^{0} 20.922$, de 17 de outubro de 2013. Dispõe sobre as políticas florestal e de proteção à biodiversidade no Estado. Publicação - Diário do Executivo - Minas Gerais 17 out. 2013.

MITSCH, W. J.; GOSSELINK, J. G. Wetlands. 4. ed. John Wiley e Sons, Inc. US, 2007. p. 582.

NEIFF, J. J.; IRIONDO, M. H.; CARIGNAN, R. Large tropical south american wetlands: an overview. In: The Ecology and Management of Aquatic-terrestrial Ecotones. Proccedings Book, University of Washington, 1994. p. 156-165. 
NEIFF, J. J. Planícies de inundação são ecótonos? In: HENRY, R. (Org.). Ecótonos nas interfaces dos ecossistemas aquáticos. São Carlos: Rima, 2003. p. 29- 46.

NRC, National Research Council. Wetlands: Characteristics and Boundaries. National Academy Press: Washington, DC, 1995. 306 p.

O.CIZEL, GHZH. Groupe d'Histoire des Zones Humides. Protection et gestion des espaces humides et aquatiques. Guide juridique, Pôle-relais Lagunes, 13 Agence de l'eau RM\&C, 2010.

PARANÁ (Estado). Res.Conjunta IBAMA/SEMA/IAP n ${ }^{\circ}$ 05, de 28 de março de 2008. Define critérios para avaliação das áreas úmidas e seus entornos protetivos, normatiza sua

conservação e estabelece condicionantes para o licenciamento das atividades nelas permissíveis no Estado do Paraná.Diário Oficial da União $\mathrm{n}^{\circ}$ 83, 2 maio 2008.

PAUL, S. Workbook for managing urban wetlands in Australia. Sydney Olympic Park Authority, 2013. Disponível em: <http://www.sopa.nsw.gov.au/_data/ assets/pdf_file/0020/804521/Editors,_Contents,_Foreword,_Preface_and_ Disclaimer.pdf $>$ Acesso em: 5 jun. 2017.

PAIJMANS, K., et al. Aspects of Australian wetlands. Ed: CSIRO Division of water and Land Resources Technical Papel n 44, Canberra, Australia, 1985.

QUEIROZ, M. L. Nascentes, Veredas e Áreas Úmidas: Revisão Conceitual e Metodologia de Caracterização e Determinação: Estudo de Caso na Estação Ecológica de Águas Emendadas - Distrito Federal. 2015. 148 f. Dissertação (Mestrado em Geociências Aplicadas) Instituto de Geociências, Universidade de Brasília, Brasília, 2015. Disponível em: <http://repositorio.unb.br/ bitstream/10482/20429/1/2015_MarinaLimaQueiroz.pdf> Acesso em: 5 jan. 2016.

RAMSAR CONVENTION. Convention on Wetlands of International Importance especially as Waterfowl Habitat. Ramsar (Iran), 2 February 1971. UN Treaty Series No. 14583. As amended by the Paris Protocol, 3 December 1982, and Regina Amendments, 28 May 1987. Disponível em: <http://www.ramsar.org/ sites/default/files/documents/library/current_convention_text_e.pdf> Acesso em: 01 mar. 2017.

REDDY, K. R; DELAUNE, R. D. Biogeochemistry of Wetlands: Science and Applications. New York: CRP PRESS, 2008. 800p.

SHAW, S. P.; C. G. FREDINE. Wetlands of the United States: Their Extent, and Their Values for Waterfowl and Other Wildlife. Editora: U.S. Dept. of the Interior, Fish and Wildlife Service. Circular 39. Washington, DC, 1956.

SCOTT, D. A.; JONES T. A. Classification and inventory of wetlands: A global overview. Vegetatio, v.118, n.1-2, p 3-16, 1995. https://doi.org/10.1007/BF00045186

SOUTH AFRICAN. Act n. 36 of 1998. Provide for fundamental reform of the law relating to water resources; to repeal certain laws; and to provide for matters connected therewith. Statutes of the Republic of South Africa - Water, n. 28, p. 1201-1399. 
TARNOCAI, C et al. The Canadian Wetland Classification System. In: Wetlands of Canada, National Wetlands Working Group and Canada Committee on Ecological Land Classification Series 24, Ottawa: Canadian Government Publications and Polyscience Publications, 1988.

TINER, R.W. Wetland Indicators: A Guide to Wetland Identification, Delineation, Classification, and Mapping. New York : CRC PRESS,1999. 418p.

WESTLAKE, D. F., KVET, J.; SZCZEPANSKI, A. The Production Ecology of Wetlands: The IBP Synthesis. London: Cambidge University Press, London, 1988. Disponível em: < http://assets.cambridge.org/97805211/13304/ frontmatter/9780521113304_frontmatter.pdf >Acesso em: 03 set. 2015

ZOLTAI, S. C. Wetland environments and classification. In: Wetlands of Canada, National Wetlands Working Group and Canada Committee on Ecological Land Classification Series 24, Ottawa: Canadian Government Publications and Polyscience Publications, 1988.

Cecília Siman Gomes - possui graduação em Geografia pela Universidade Federal de Minas Gerais, mestrado em Geografia e Análise Ambiental pela Universidade Federal de Minas Gerais. Atualmente participa do grupo de pesquisa Geomorfologia e Recursos Hídricos na Universidade Federal de Minas Gerais (IGC-UFMG). Tem experiência profissional na área de Ciências Ambientais, com a elaboração e coordenação de estudos socioambientais.

Antônio Pereira Magalhães Júnior - possui graduação em Geografia pela Universidade Federal de Minas Gerais, mestrado em Geografia e Análise Ambiental pela mesma Universidade. Doutorado em Desenvolvimento Sustentável pela Universidade de Brasília e pós-doutorado no Departamento de Geografia da Universitat Autònoma de Barcelona. Atualmente é professor da Universidade Federal de Minas.

\section{Contribuições dos autores}

O artigo foi elaborado de maneira integrada entre os autores, coletando informações e analisando os resultados originários da pesquisa de mestrado da primeira autora, defendida em setembro de 2016 no Instituto de Geociências - Universidade Federal de Minas Gerais, sob orientação do professor Antônio Pereira Magalhães Júnior. Neste sentido, o artigo é resultado de nossas pesquisas conjuntas na área de gestão de sistemas hídricos continentais. 